\title{
CEZA HUKUKUNDA MEMUR KAVRAMI (Kamu Menfaati İçin Görevlendirilmiş Şahslar)
}

\author{
Prof. Dr. Doğan SOYASLAN*
}

Kamu menfaati için yetkilendirilmiş şahıslan inceleme ve bunların kimliğini belirlemeden, Devlet idaresi aleyhine işlenen suçlann içeriğine nüfuz etmek mümkün değildir. Çünkü Devlet idaresi aleyhine işlenen suçların büyük kısmı sadece bu şahıslar tarafından veya bu şahıslara karşı işlenmektedir.

Kamu menfaatine çalışan personel kavramı çok geniş bir kavramdır. Bu konuda Türk hukukuna geçmeden önce kaynak ülke kanunu'nu hem teorik ve hem de uygulama açısından incelenmekte fayda vardır.

\section{I- İtalyan Ceza Kanunu}

1889 Tarihli Italyan Ceza Kanunu 207. maddesinde sadece memur kavramını düzenlemişti. "Kanunun memur saydığı kimseler şunlard:

1. Devletin, Belediyelerin, Vilayetlerin, Devletin, Belediye ve Vilayetlerin vesayeti altında bulunan bir kurumun hizmetinde geçici veya devaml, ücretli veya ücretsiz çalışan kişiler.

\section{Noterler.}

3. Adli organ nezdinde çalışan mübaşirler,

Jüri üyeleri, hakemler, bilirkişiler, tercümanlar, tanıklar da görevlerini icra dolayısıyla memur sayılmakta idiler.

1930 Tarihli Kanun kavramların bölünmesinde geleneksel eğilime sadık kalarak kamu menfati için çalışan personeli yeniden dïzenlemiş, memur kavramının yanında iki kategori personel daha

* A.U. Hukuk Fakultési Ceza Hukuku Anabilim Dalı Ögretim Uyesi. 
ihdas etmiştir. Bunlar kamu hizmetlileri ve amme için zorunlu hizmet icra eden personeldir.

Gerçekten İtalyan Ceza Kanunu'nun 357. maddesine göre memur şöyle tanımlanmıştır.

1. Devlet veya bir başka kamu kurumunda devamlı veya geçici olarak çalışan adlî, idarî, teşrii görev yapan kişi;

2. Devamlı veya geçici, ücretli veya ücretsiz, ihtiyarî veya mecburî adli, idari, teşri bir kamu görevi yapan kişiler memur sayılir. miştir.

358. madde Ceza Kanununda kamu hizmetlisini şöyle düzenle-

1. Devamlı veya geçici olarak devlet veya diğer bir kamu kurumu adına amme hizmeti görenler.

2. Devamlı veya geçici, ücretli veya ïcretsiz, ihtiyari veya mecburi olarak amme hizmeti görenler kamu hizmetlisi sayllırlar.

359. madde ise Ceza Kanunu'na göre amme için zorunlu hizmet yapanları tarif etmiştir.

1. Avukatllk veya sağlık mesleği icra eden özel şahıslar, Kanunun, icra edilmesi için devlet tarafından kazandırılan bir yeteneği aradığ meslekler, (Doktorlar, ebeler, eczacılar, mühendis ve mimarlar gibi).

2. Kanunun, toplumu icra edilen mesleği amme için zorunlu hizmet olarak kabul etmeğe mecbur ettiği meslekler,

3. Ne kamu hizmeti ve ne de kamu görevi görmeyip te, bir idari işlem ile yaptığı hizmet kamu için zorunlu sayılan hizmeti yapanlar, kamu için zorunlu hizmet yapıyor sayılırlar (Un öğütücüleri, ilaç üretenler, taksiciler, tuz ve tütün satanlar, döviz satıcılanı gibi).

Bu üç maddenin yorumu İtalya'da hem teori ve hem de uygulamada birçok güçlük, kararsızlık ve tartı̧̧malara sebebiyet vermiştir. İtalyan Yargıtayı bu konuda birçok karar vermeğe mecbur olmuş, 
verdiği kararlarda sayısız çelişki görülmüş, ölçüsüz bir şekilde memur kavramı genişletilmiş, hatta büsbütün keyfilik yapılmıştır'.

Adı geçen yükssek mahkeme 1932 tarihinde verdiği bir kararda doktoru memur, 1941 de ise kamu hizmetlisi, 1933 de ilkokul ögretmenlerini kamu hizmetlisi, 1937 de memur, mektup dağıtıcısını 1934 de memur 1935 de kamu hizmetlisi, 1966 da bankada çalışanı kamu hizmetlisi 1973 de memur saymıştır².

Manzini'ye göre üniversite odacısı, itfaiye görevlisi memur, meclis kütüphane görevlisi memur, stenografi kamu hizmetlisidir. Nedeni belirsizdir ${ }^{3}$. İtalyan Yargıtayına göre ise odacı da itfaiyeci de kamu hizmetlisidir.

Faşist rejim döneminde Cumhuriyet Savcılıklarının istemi üzerine memur kavramı genişletilmiş, devlet iştiraklerinin çoğalmasıyla sorun daha da büyümüş, bu kurumlann fizyonomisinin farklılığı kanun hükümlerinin uygulanmasını güçleştirmiştir.

Geçmişte sorunu artıran bir başka faktör de bazı özel kanunların kendi personellerini memur saymaları olmuştur. Gerçekten 22 Nisan 1905 tarihli demiryollarına ilişkin kanun tüm demiryolu personelini memur sayıyordu. 22 Nizan 1905 tarihli kanunun yerini 7 Temmuz 1907 tarihli kanun almıştır.

20 Aralk 1923 tarihli Telgraf, Telefon, Radyo'ya ilişkin kanun personelini memur sayıyordu. Bu kanunlar, doktrinde karşı fikre rağmen Ceza Kanunu'nun 357, 358 ve 359. maddeleri tarafindan zımnen ilga edilmiş sayılmayarak yürürlüikte kabul edildi. İtalyan Anayasa Mahkemesi 7 Temmuz 1907 tarihli Kanunun 56. maddesini (bu madde tüm demiryolu personelini memur sayıyordu) Anayasaya aykırı bularak iptal etti (Karar 26 Haziran 1974) ${ }^{4}$.

29 Mart 1973 tarihli D.P.R., 12. maddesi Posta, Telefon, Telgraf memurlarının Ceza Kanununun 357 ve 358. maddelerine tabi olduğunu kabul etti ${ }^{5}$.

1. Antolisei: Manuale di diritto penale, parte speciale, Vol. II, 7. ma Edizione, Milano 1977, sh.705.

2. Antolisei, II, sh. 705, Dipnot No: 5,6 .

3. Antolisei, II, sh. 706, Dipnot 6. mn devam1.

4. Antolisei, II, sh. 707 .

5. Antolisei, II, sh. 707 . 


\section{II- Türk Ceza Kanunu}

Kamu menfaatine çalışan personel, Kanunun 279. maddesinde düzenlenmiştir. Bu kapsama mehaz kanun kabul edildiğinde sadece devlet memurlari sokulmuştur.

1930 tarihli İtalyan Ceza Kanunu'nun üç kategori personel kabul etmesinden etkilenen Türk Kanun koyucusu 1936 yllnda 3038 sayılı Kanunla diğer değişikliklerin yanında 279. maddeyi de değiştirdi. Gerçekten söz konusu değişikliğge göre, yeni İtalyan Ceza Kanununun 357 ve 358. maddelerinde tarif edilen devlet memuru (I. fikra) ve kamu hizmetlisi gibi iki kategori kamu menfaatine çalışan personel hemen aynı ifadelerle 279. maddede düzenlenmiş̧, amme için zorunlu hizmet yapanlar (I.C.K. md. 359) madde kapsamı dışında tutulmuştur.

Oysa amme için zorunlu hizmet yapanlann da düzenlenmesi ve bunların görevleri ile ilgili işledikleri suçlar veya görevleri esnasında bunlara karşı işlenen suçların da özel hükümlerle kanunda yerini almıs olması isabetli olurdu. Meselâ doktor, eczacı, kimyager, mühendis ve mimarlann cezalandınlması ve korunması gibi.

Aslında devlet memurlarından ayn olarak kamu hizmetlileri kategorisinin düzenlenmesi de bir şeyi değiştirmemiştir. Çünkü İtalyan kanunun 279. maddesine aktarlmıs ama buna paralel olarak özel hükümlerde suçun kamu hizmetlileri tarafından işlenmesi haline ilişkin değişiklik (birkaç istisna hariç) bilinçli bir şekilde gerçekleştirilmemiş̧ir. $O$ halde böyle bir değişikliğin pratikte bir yararının olup olmadığı sorusu akla gelebilir.

Ancak memuru tarif eden madde 1936 yilinda İtalyan Ceza Kanununa paralel olarak deł̧iştirildiğine göre hükmün anlam ve kapsamını açıklamakta zaruret vardır. Kamu hizmetlileri, amme için zorunlu hizmet yapanlar özel hükümler arasında düzenlenmediğine göre memur kapsamına girmeyen fail kamu hizmetlisi veya amme için zorunlu hizmet yapanlar kapsamına girmeyecek, sadece normal özelkişi sayılacaktır.

Türk Ceza Kanunu'nun 279. maddesinde kamu için çalışan iki kategori personel düzenlenmiştir. Memurlar ve kamu hizmetlileri.

6. Eman: Ceza Tatbikat ve Takibatinda Memur, Siyasal Bilgiler Okulu Dergisi, Ankara 1947 , sh. 240 . 
“Ceza Kanunu'nun tatbikatında;

1) Devamlı veya muvakkat surette teşrîi, idarî veya adlî bir amme vazifesi gören Devlet veya diğer her türlü amme müesseseleri memur, müstahdemleri;

2) Devaml veya muvakkat, ücretsiz veya ücretli, ihtiyari veya mecburi olarak teşrii, idari veya adli bir amme vazifesi gören diğer kimseler memur sayılır.

Ceza Kanunu'nun tatbikatında amme hizmeti görmekle muvazzaf olanlar:

1) Devaml veya muvakkat suretle bir amme hizmeti gören Devlet veya diğer amme müessesesinin memur ve müstahdemleri;

2) Devamlı veya muvakkat, ücretli veya ücretsiz ihtiyar̂ ve mecburî surette bir amme hizmeti gören diğer kimselerdir".

Kanun metninden çıkan neticeye göre bir kişinin memur veya kamu hizmetlisi sayılması için, bir kamu kurumu ile iş anlaşması yapmıs olması gerekmez. Başka bir ifadeyle kişi ile kamu kunumu arasında bir anlaşma sonucu kişinin kurum lehine devamlı şekilde mesleki görevini icra etmesi ve bunun sonucunda bir miktar para alması sözkonusu değildir.

O halde gerek kamu görevlisi memur ve gerekse kamu hizmetlisi personeli kendi adlarına çalışan özel şahıslar da oluşturur.

Gerek kamu görevinin ve gerekse kamu hizmetinin icrası devamh olabileceği gibi geçici de olabilir.

Hizmet icrasının paralı veya bedava, ihtiyari veya mecburi olmasının önemi yoktur.

Memur ile kamu hizmetlisi arasındaki ayırım konusunda Kanun, icra edilen fonksiyonun mahiyetine bakmaktadır. Gerçekten kanuna göre kamu görevi icra eden memur, kamu hizmeti icra eden ise kamu hizmetlisidir. $O$ halde bu iki kategori personel arasındaki ayırım kamu görevi ile kamu hizmeti arasındaki farka bağlıdır?.

7 Antolisei, II, sh. 707. 
Ancak bu farkı kanun belirtmemiştir. Proje üzerinde bakanlık raporunda kamu görevi ve kamu hizmeti kavramı üzerinde doktrinde yazılanlar teyid edilmiştir. Bu konuda kanunda açıklık olmadiğından problemin çözümüinü Ceza hukuku alanında değil, İdare hukuku alınında aramak gerekir.

Aslında maddenin düzenleyicileri bilimin bu konuda belli neticelere ulaştığı önyargısından hareket ettiler. Başka bir ifadeyle kanunu yapanlar, kamu görevi kavramı ile kamu hizmeti kavramı üzerinde belli neticelere varıldığı kanaatinde idiler. Oysa böyle bir netice sadece faraziye olup gerçeğe uymuyordu. Bu konuda doktrin o kadar ihtilaflıdır ki hâkim fikir bile var demek mümkün değildir”.

Kamu görevini, kamu hizmetinden ayırmak ve bu konuda çıkan sorunu çözmek için ileri sürülen fikirleri üç ayrı grupta toplamak mümkündür.

1) Bazı yazarlara göre, kamu görevinin özelliği, kamu kurumunu temsil etmektir. Daha açık bir ifadeyle kurumun iradesini şekillendirme, belirleme gücü veyahutta iradeyi şekillendirme ve belirlemeye iştirak etmek ve bu iradenin icrasında kurumu temsil etme gücüne sahip olmaktır.

Kamu hizmeti de amme için ifa edilen bir görevdir. Ancak yukanda belirtilen özelliklere sahip değildir. Öte yandan kamu hizmeti zorunlu kamu hizmeti kavramına da girebilir'.

Bu kriter kendi başına yeterli sayılamaz. Çünkü memur sayılmaması mümkün olmayan birçok kimseyi kapsamına almamaktadır. Meselâ tanıklar, bilirkişiler, adli yorumcular ve özellikle noterler gibi ${ }^{10}$.

2) Diğer hukukçular ayırımı, Devlet idaresinin faaliyetinin hukuki veya sosyal faaliyet olup olmadığına göre yapmaktadırlar". yettir.

Hukuki faaliyet devletin esaslı ve temel amacına uygun faali-

8. Antolisei, II, sh. 708 .

9. Antolisei, Il. sh. 708 .

10. Antolisei, If, sh. 708 .

11. Erman, a.g.m., sh. 708 . 
Sosyal faaliyet ise toplum için sadece faydalı faaliyettir. Bu ikinci faaliyetin niteliği toplum fertlerinin fiziki, ekonomik ve entellektüel iyilikleri için yapılmasıdır. İşte bu teoriye göre devletin esaslı faaliyetine giren görev kamu görevi, ikinci gruba girenler ise kamu hizmetidir ${ }^{12}$.

Devletin faaliyetinin hangisinin esasl, hangisinin esassız olduğu konusuna haklı olarak ciddi itirazlar yöneltilmiştir. Bu kriterin kabulü halinde memur ile kamu hizmetlisini birbirinden ayırmaya imkan yoktur. Devlet idaresinin sosyal faaliyetlerinden olan bazı faaliyetleri icra edenlere memur sıfatını atfetmemek mümkün değildir. Meselâ Sosyal sigortalar kurumu genel müdürünü memur saymamak imkansızdır.

Buna karşılık devletin temel faaliyeti arasına giren birçok faaliyet kapsamında çalışan kişileri memur kapsamına sokmak mümkün değildir. Meselâ milli savunma, kamu nizamıni muhafaza eden güvenlik güçleri çalışanları, Adliyede çalışanlar gibi ${ }^{53}$.

3) Bir, üçüncü akıma göre kamu görevi emir verme ve kumanda etme yetkisini, kamu hizmeti ise böyle bir yetkiyi içermez ${ }^{14}$. Bu yetki, kendisini icra edenin diğerleri üzerinde güç sahibi olması, vatandaş karşısında hukuken üstün bir gücün tezahürü ve gücü kullanma hakkı olarak kendisini gösterir.

Bu fikre karşı da itiraz edilmiştir. Emir verme yetki ve iradesi, üstün bir yetki ve faaliyeti içermektedir. Bu yetki ve faaliyete, devlet idaresi içinde idare adına görev icra eden birçok kişi sahip değildir. Sahip olamaz da. Meselâ kamu adına belge düzenleyen ve kamusal faaliyeti belgeleyen adli katipler, nüfus memurları, noterler ve kambiyo memurları gibi.

Bu kriterlerin yetersizliği, birçok hukukçuyu adı geçen fikirleri telif etmeye sevketti. Birçok karma teori ileri sürüldü. Bunlara başka kriterler de eklendi. Maddi işlemler, fikri işlemler, takdiri işlemler, takdiri olmayan işlemler ayırımı gibi's. .

12. Santoro, A.: Manuale di diritto penale-parte speciale, C.11, Torino 1962, sh. 234.

13. Antolisei, II, sh. 709 .

14. Erman, a.g.m., sh. 246; Santoro, II, 1962, sh. 234.

15. Antolisei, II, sh. 709 . 
Antolisei'e göre kamu görevi kavramı jle kamu hizmeti kavra$\mathrm{m}$ arasına ayırıcı bir hat koymanın güçlüğ̈̈ birçok engel nedeniyle aşılamaz. İdare hukuku bilimi kamu görevi ile kamu hizmeti kavramlarının sınırını çizememiş, hatta büyük İdare hukukçuları tarafından da bu fark inkâr edilmiştir. Çünkü ikisi de amme için ifa edilen görevlerdir. Modern hukuk nizamlarında kamu görevi karmaşık bir karakter arzetmektedir. Birçok çeşidi olup sayısız dereceleri vardır. Bu nedenle kamu görevinin nerede bittiği, kamu hizmetinin nerede başladığı çöziilmesi gereken güç bir sorundur ${ }^{16}$.

Ünlü Ceza hukukçusuna göre sorunu çözmek mümkün olmamakla beraber tereddütleri azaltmak amacıyla aşağıdaki kriterlerden yararlanmak mümkündür ${ }^{17}$.

aa) İdarî işlemlere entellektiiel, fikrî katkısı ile kurumun iradesinin oluşmasına katkıda bulunan şahıslar, kurumun iradesini oluşturan kimseler memur, oluşturmayanlar kamu hizmetlisidir.

O halde kurum adına fikir üreten, idari sekreterler, mühendisler, muhasebeciler memurdurlar.

bb) Kamu kurumu adına direktif verme görevi icra edenler memur, böyle bir görevi olmayanlar kamu hizmetlisi sayılacaktır.

cc) Kurumu dışa karşı hangi bir şekilde temsil eden şahıslar memur, etmeyen şahıslar kamu hizmetlisi sayılacaktır.

dd) Otorite yetkileriyle donatılanlar memur, donatılmayanlar kamu hizmetlisi sayılacaktır. Özellikle yakalama ve tutma yetkisine sahip olanlar ile kabahatlerden dolayı cezalandırma yetkisine sahip olanları memur saymak gerekir. Bu kategorinin içine özellikle güvenlik güçleri mensupları, gemi kaptanları, polis görevi ifa eden bekçiler, suçun meşhut olması durumunda öngörülen vatandaşın yakalama yetkisi halinde yakalama, Demiryollan ve tranvaylardaki bilet kontrolörleri, Devlet iştiraklerinde çalışan ve kanunların ihłâl edilip edilmediğini araştıran ilgili sertifakaların doğru olup olmadığını inceleyen kişiler keza memur sayılırlar ${ }^{18}$.

ee) Belge ve delil niteliğinde sertifika düzenleme ve dïzenletme yetkisi ile donatılmıs olan, hukuk düzenine göre delil kuvvetin-

16. Antolisei, II, sh. 710 .

17. Antolisei, II, sh. 711 .

18. Antolisei, II, sh. 712 . 
de döküman düzenleme yetkisine sahip olanlar memur sayılmalıdır. Noterler, kambiyo memurları, izin verilmiş aracılar vs. Bu kategoriye muhakemede adli organlarla işbirliği yapan şahtslar da sokulabilir. Bu şahıslar delil olacak şeyleri ifade ve kabul ederler vs ${ }^{19}$.

Zorunlu kamu hizmeti ifa edenlerin dışında, kamu menfaati için görev ifa eden tüm diğer şahıslar kamu hizmetlisi sayılmalıdırlar. Kisacası bu kategoriye girenler zorunlu kamu hizmeti ifa edenler ile memurların dışında kalan kategoriyi oluştururlar.

İtalyan yargıtayı 30 Ekim 1968, 14 Mayıs 1976, 6 Ekim 1965 tarihli kararlannda kamu hizmetlisi kavramina, idarenin bünyesinde memurlara yardımcı olan tüm görevlileri sokmuştur. Sosyal amaçı bir hizmetin yapılmasını kamu hizmeti, yapanı kamu hizmetlisi saymıştır ${ }^{20}$.

Netice olarak Antolisei şu kanate ulaşmaktadır. 279 madde kanş̧klı̆ga ve keyfiliğe sebebiyet vermektedir. Zanardelli Kanunu'nun formülüne dönülmelidir. Sadece bir tek kavrarn kalmalıdır. Bu kavram memur veya kamu fonksiyoneri kavramıdır. Bugünkü ayınm Ceza Hukuku'nun amaçlan açısından zorunlu bir ayırım olmayıp ayrıca kötï neticeleri de olan bir ayırımdır. Meselâ zimmet, ihtilas, irtikap suçlarını memurlar işlemektedir. Bu fiilleri yetkilerini suistimal ederek pekâlâ kàmu hizmetlilerinin de işlemesi mümkündür. Böyle bir fíli özel hükümle daha ağı bir şekilde cezalandırmamak için sebep yoktur ${ }^{21}$.

Aslında bizce de kamu görevi ile kamu hizmeti arasında fark yoktur. Belki derece farkı vardır. Ancak ikisi de kamu görevidir. Ceza hukuku böyle bir ayırım yapmakla kendi açısından sonucu büyüitmüştür. Bunun nedeni bir yandan görevin ihlâli veya suistimali halinde memura daha ağır bir sorumluluk yüklemek, diğer yandan memuru görevi dolayısıyla muhtemel tecavüzlere karşı daha fazla korumak istemektir.

Gerçekten İtalyan Ceza Kanunu, memuru, görevini ihlâl ve ihmallerinde, kamu hizmetlisine göre daha fazla cezalandımaktadır. Keza memura karşı tecavüzlerde bulunan özel kişiler de kamu hizmetlisine tecavüze göre daha fazla cezalandırılmaktadır. Bu ceza farkının nedeni, maddeyi düzenleyenlerin gözünde memurlann

19. Antolisei, II, sh. 712 .

20. Antolisei, 1I, sh. 712.

21. Antolisei, II, sh. 7213 (ve dipnot 19). 
daha nazık ve yüksek bir görev icra etmeleri ve bunun tabiî sonucu vazifelerini suistimalleri halinde daha ağır cezalandırılmaları veya bunlara karşı görevin ifası dolayısıyla suç işleyen özel şahıslann daha fazla cezalandırılmasıdır.

Türk hukukunda ise menur ve kamu hizmetlisi ayırımı 279. maddede mevcut, ancak özel hükümlerde mevcut değildir. $O$ halde memur ile kamu hizmetlisi arasında ayırıcı kriter aramak boşunadır. Bu incelemenin pratikte tek faydası memur olanla olmayanı, özel şahısłarı birbirinden ayırmakta karşımıza çıkmaktadır. Bunun çözümii süreli, süresiz, paralı, parasız, amme için görev yapan herkesi kamu görevlisi, dolayısıyla memura saymak, başka bir ifadeyle mehaz kanunun çözümüne dönmektir.

Böyle bir geriye dönüß̧ benimsendiğinđe kamu görevlisinin vazifesi dolayısıyla suç işlemesi veya görevliye karşı suç işlenmesi hallerinde hakimin ceza takdir yetkisini, alt ve üst sınırları geniş tutmak, hakime icra edilen görevin yüksekliği ve önemine göre manevra alanı tanımak isabetli olur. $O$ halde bu incelemenin pratikte tek faydası memur olanla olmayanı yani özel şahıslan ayırmakta karşımıza çıkmaktadır.

Uygulamada Yargıtay genel olarak hangi kurumda çalışırsa çalışsın odacı ve hizmetlileri, şöforleri, biletçileri, bekçileri, mahalle muhtarlarını, imamları devlet memuru saymamaktadır (4. C.D. 9.4.1991-1449/2309) (4. C.D. 14.5.1991-2004/2891) gibi.

Memurluk veya kamu hizmetliliği ayırımının kolayca yapılamayışı, esasen kamu hizmetlisinin suç işlemesi halinde uygulanacak olan yaptırımın normal vatandaşa uygulanacak yaptırımdan farksız oluşu kanun koyucuyu, kuruluş ve işleyiş kanunlarını düzenlediğj kurumların personelini açıkça memur saymaya itmiştir.

Gerçekten 2495 sayılı kanununun 13. maddesine göre Tariş personeli, 506 sayılı kanunun 136 ve 4792 sayll kanunun 7 . maddesine göre Sosyal Sigortalar Kurumu memur ve hizmetlileri, 2929 sayılı Kanunun 48. maddesine göre KİT personeli memur sayıImı̧tIr.

III- Memuriyet Sıfatının Kaybına Rağmen Memuriyetin Devamı (Fiil ile sıfat arasındaki münasebet)

Kamu menfaati için görevli personelin işlediği suçlar özelliği olan suçlardır. Kamu personeline ait suçtan söz etmek için fiil ile 
sıfattan doğan faaliyet arasında bir bağ olmalıdır. Bu bağ üç şekilde kendini gösterir.

Fiil görevin veya bizmetin ifası dolayısıyla, yani görevi icra anında işlenir. Meselâ irtikap suçunda başkasının hatasından istifade ile fiili işlemek söz konusudur (md. 209/3).

Bazı hallerde görevin icrası suçun belirleyici unsuru olarak ortaya çımaktadır. Bu hallerde fiiller, görev veya hizmet sebebiyle gerçekleşmelidir. Memura taaruz ve hakarette olduğu gibi (md. 266).

Diğer bazı hallerde de fiil ile görev arasında amaç açısından bağ vardır. Meselâ rüşvet suçunda memur kendi görevi dahilinde olan bir işi yapmak için rüşvet almalıdır (md. 212-213) ${ }^{22}$.

Bu hükümlerden şu anlam çıkmaktadır. Kamı görevlileri görevden ayrilmış bile olsalar idareyi temsil etmektedirler.

İdare ile birleşmişlerdir. Kanunen emekli olsalar, istifa etseler veya görevden alınsalar da cezalandırılmalanının sebebi budur. Ayrıca fiil memurun ifa ettiği görev ve hizmet ile ilgili olmalıdır. Memurun Devlet memuru iken öğrendiği sırrı, emekli olduk veya görevden ayrildıktan sonra açiklamasında, durum budur. Memur olmayan kimse bu suçları işleyemez.

Bazen memurluk suçun ağırlatıcı sebebidir. Adam öldürme (md. 450/11) ve müessir fiil suçlarında olduğu gibi (md. 457/2).

Memuriyetin suçun unsuru olması halinde, eğer memur suçu görevi dolayısıyla işlemiş ise artık memur olmasa bile memur gibi cezalandırılur (md. 280).

Ĕ̆er memur görevi nedeniyle suç mağduru olmus ise görev anında olmasa veya memuriyetten sonra mağdur da olsa mağdur memur olarak korunacaktır.

Memuriyetin suçun ağırlatıcı sebebi olmast halinde (ağırlatıcı sebep olmasının nedeni fiilin görev nedeniyle işlenmesidir) memuriyet sona erse veya fiilin işlendiği anda memur görevi başında bulunmasa da, mağdur memur sayılmaya devam edecektir (md. 280).

22. Antolisei, II, sh. 714. 
Bu hükümlerden çıkan sonuca göre bir polisin görev yaparken birisini yakalamasından dolayı, emekli olduktan sonra yakalanan kişi tarafından dövülmesinde ağırlatıcı sebepler uygulanacaktır.

\section{Suçun İşlenmesinde Memuriyet Kuvvet ve Vasitalan- nin Kullanilması}

Md. 281. "Bir kimse cürüm işlemek için haiz olduğu memuriyete ait kuvvet ve vasttalan kullandığı takdirde eğer kanun esasen memuriyet sıfatın nazarı itibara almamış ise irtikap olunan cürüm için tayin olunacak ceza altıda birden üçte bire kadar tezyit olunur."

Devlet memurunun kamu gücünü veya görevinin verdiği imkanları kullanarak sụ̧ işlemesi halinde devlet idaresinin itibar've prestiji zarar görür. İşte bu nedenle kanun koyucu memurluğun kişiye bahsettiği imkan ve vasıtaları kullanarak suç işlenmesini genel bir ağırlatıcı sebep saymıştır.

Kanun bazen devlet memurunun görevini kullanarak suç işlemesini bir suçun unsuru (md. $181,183,184,245$ ) veya ă̆ırlatıcı sebebi (md. 406) saymıştır.

Ancak bunlar gibi özel hükümlerin dışında genel bir ağırlatıcı sebep ile de kamu idaresini korumak gereğini duymuştur. İşte 281 . madde bu fonksiyonu yerine getirmekte memurun görevini suistimal ederek herhangi bir suç işlemesini cezada artırım sebebi saymaktadır.

Şahıstan kaynaklanan bir ağıllatıcı sebeptir.

Ağırlatıcı sebebin aktif sujesi sadece memur olabilir.

Memurun işlemiş olduğu suç cürüm olmalıdır. Kabahatler ceza artırım nedeni olamaz. Fiil kasden işlenmelidir. Taksirle işlenenler madde kapsamına girmezler.

Memur fail kamu hizmetinin yürütülmesi için kendisine verilmiş yetki ve vasıtaları kullanarak suçu işlemelidir. Hizmetin gereği hukuka uygun olarak kullanılması gereken yetki ve vasıtalar hukuka aykırı olarak kullanlmak suretiyle suistimal edilmelidir ${ }^{23}$. Me-

23. Manzini: Trattato di díritto penale ltaliano, Vol. V, Milano-Torino-Roma 1913, sh. 58. 
muriyet yetki ve vasıtalan ile, işlenen suç arasında amaç araç bağlantısı olmalidir.

Ağırlatıcı sebebin uygulanmasi için fiilin kasten işlenmeși gerekir. Fail memur memuriyet yetki ve vasıtalannı amacı dışında kullanarak suç işlediğini bilmelidir.

Yargıtay, sanuk emniyet görevlisini, emniyet hizmetleri sınıfı personeline ait tabanca ile suç işlemesi halinde memuriyet vasıtasına kullanmaktan dolayı cezanın artınlması gerektiğine karar vermiştir (1. C.D. 10.5.1993-691/1018). Köy muhtarının köy demirbaŞına kayıtlı olan silahı kavgada korkutmak amacıyla kullanması halinde 281. maddenin uygulanması gerektiğine işaret etmiştir (1. C.D. 21.11.1991-2488/2802). 